\title{
The association between personality disorders/traits and violent eye trauma
}

\author{
Mohammad Reza Mansouri ${ }^{1}$ - Seyed Ali Tabatabaei ${ }^{1}$ - Morteza Naderan ${ }^{1}$ - Mohammad Soleimani ${ }^{1}{ }^{1}$ • \\ Fatemeh Minaei Zangi ${ }^{1}$ • Dianaalsadat Matini ${ }^{1}$
}

Received: 7 December 2017 / Revised: 7 December 2018 / Accepted: 23 February 2019 / Published online: 11 March 2019

(c) The Royal College of Ophthalmologists 2019

\begin{abstract}
Aims To determine the prevalence of various personality disorders in patients with open globe injuries caused by violent eye trauma.

Materials and methods One-hundred patients were divided equally to case and control groups. The case group was selected from admitted patients with open globe injury following a violent act. We considered open globe injuries not involved in violence as the control group. All patients interviewed using SCID-II questionnaire.

Results The mean age was 30.7 \pm 9.2 year and $34.4 \pm 13.1$ year for the case and control groups, respectively, $(P>0.05)$. The married population was more frequent in the control group $(P=0.027)$. Forty-three patients $(86 \%)$ in the case group and 23 patients $(46 \%)$ in the control group demonstrated some personality disorder $(P<0.001)$. In both groups, cluster B was most frequent. The antisocial personality disorder was more prevalent in the case group. $(P=0.046$ and $P=0.006$, respectively). The ocular trauma score (OTS) and the mean visual acuity was significantly worse in the case group $(P=0.028$ and $P=0.044)$.

Conclusions Personality disorders are probably important factors in those who acquire an open eye injury during violent behavior. This group had a poor visual outcome. We suggest that this population merits appropriate psychiatric consultation for detection of personality disorders.
\end{abstract}

\section{Introduction}

Ocular trauma remains the major contributor for monocular blindness worldwide [1]. However, it is probably an underrecognized injury because most patients are managed without hospitalization [2]. It is usually attributed to accidental events in the workplace, traffic accidents, sport courts, and recreational activities. Implementation of appropriate safety measures has led to the reduced chance of injury in such settings [3]. Yet, accidental or advertent eye damage may happen in a public or domestic violent scene. Unfortunately, violence-related ocular trauma has allegedly been increasing in the past decades and studies demonstrate violence as a leading cause of emergency department visits

Mohammad Soleimani

Soleimani_md@yahoo.com

1 Eye Research Center, Farabi Eye Hospital, Tehran University of Medical Sciences, Tehran, Iran for eye injuries [4-7]. Most subjects involved in violent behavior are young, and the lifelong impact of the resulting morbidity may be quite burdensome in both personal and societal terms $[2,8]$.

Violence absorbs a lot of interest as a remarkable public health issue $[9,10]$. There has been a postulation that mental illness and personality disorders (PDs) contribute to committing violence with a body of literature supporting this idea [11]. Nevertheless, it should be emphasized that violence is a result of an intricate combination of personal, interpersonal, cultural, and environmental causes and a simplistic view should be avoided [12].

In spite of apparent association between psychopathologic conditions and personality disorders, it is not known whether people with personality disorders are more vulnerable to sustaining non-psychiatric morbidities. This question is important from the public health point of view [8]. To the best of our knowledge, the literature is void of data regarding the association between personality disorders and eye trauma in a controlled study. We designed the 
current research to determine the incidence of various personality disorders in patients who have sustained open globe injury in a violent act and to compare them with a control group.

\section{Materials and methods}

This is a case-control study designed and conducted in the Farabi Eye Hospital, Tehran, Iran in 2016. The research design was approved by the hospital's ethics committee and the Tehran University of Medical Sciences' ethics department regarding concordance with the codes of the declaration of Helsinki. Informed consent was obtained from each individual regarding participation in a clinical research study in which in addition to taking care of their ophthalmologic condition, a psychiatrist would interview them for solely research purposes.

The sample size was calculated based on a pilot study performed in the same location by the same authors. The participants were recruited from the patients presented to the emergency department of the Farabi Eye Hospital in a nonrandomized simple sequence.

The cases were selected from patients suffered an open globe injury during a violent act. The controls were selected from patients inflicted during any event, such as occupational, recreational, and traffic events, except for violence.

Patients under 16 years of age were excluded. Likewise, debilitated and poorly cooperating patients were excluded. The management course of the open globe injury was determined at the ophthalmologist's discretion.

A psychiatric evaluation was performed by a single psychiatrist using the SCID-II questionnaire [13]. This is a semi-structured clinical interview for DSM-IV axis-II disorders, namely, personality and developmental diseases. The validity and reliability of the Persian format of this questionnaire were proved in previous studies [14-16]. The attending psychiatrist was masked as what the background for the eye injury might have been.

We used Kolmogorov-Smirnov test and Q-Q plot to assess normal distribution of data. To describe data, we used frequency and percent, mean $\pm \mathrm{SD}$, median, and range. To evaluate the difference between the two groups in baseline we used the $t$-test, Mann-Whitney U, ChiSquare, and Fisher's exact test. Relation of different factors with personality disorders was evaluated by Spearman correlation coefficient and Mann-Whitney U tests. The statistical analysis was accomplished by SPSS software (IBM Corp. Released 2014. IBM SPSS Statistics for Windows, Version 23.0. Armonk, NY: IBM Corp.). A $p$-value less than 0.05 considered statistically significant.

\section{Results}

One-hundred patients were enrolled in the study with equal contribution to the case and control groups. Table 1 represents the demographic features of the study population. It is clear that both groups were similar regarding age and gender. In contrast, we found a difference in the marital status between cases and controls, where single patients outnumbered married patients in the case group and vice versa in the control group. No difference was detected in the laterality of injury. Regarding the type of ocular damage, the penetrating injury was found more often in the control group while globe rupture was observed more frequently in the case group. Wound dehiscence, of previous corneal graft or repair, was only seen in the case group. We did not find any difference in the level of education between the study groups.

Three patients (3\%) in our study underwent enucleation surgery: two (4\%) in the case group and one (2\%) in the control group. The statistical difference was not significant. The cause of eye injury in the violence included unarmed combat with the punch in $14(28 \%)$, glass piece in $6(12 \%)$, knife in 10 (20\%), and some other devices used for bullying the opponent in 17 (34\%). Three patients $(6 \%)$ was injured due to gunshot injury.

Table 2 represents various personality disorders among the study population. It is worth mention that one person

Table 1 Characteristics of the study population

\begin{tabular}{|c|c|c|c|c|}
\hline Variable & & $\begin{array}{l}\text { Case } \\
(n=50)\end{array}$ & $\begin{array}{l}\text { Control } \\
(n=50)\end{array}$ & $P$ value \\
\hline Age & & $30.7 \pm 9.2 \mathrm{y}$ & $34.4 \pm 13.1 \mathrm{y}$ & 0.404 \\
\hline \multirow[t]{2}{*}{ Gender } & Male & $43(86 \%)$ & $47(94 \%)$ & 0.182 \\
\hline & Female & $7(14 \%)$ & $3(6 \%)$ & \\
\hline \multirow[t]{2}{*}{ Marital status } & Single & $28(56 \%)$ & $17(34 \%)$ & 0.027 \\
\hline & Married & $22(44 \%)$ & $33(66 \%)$ & \\
\hline \multirow[t]{3}{*}{ Laterality } & OD & $24(48 \%)$ & $19(38 \%)$ & 0.329 \\
\hline & OS & $25(50 \%)$ & $31(62 \%)$ & \\
\hline & $\mathrm{OU}$ & $1(2 \%)$ & 0 & \\
\hline \multirow[t]{5}{*}{ Education } & Illiterate & $2(4 \%)$ & $2(4 \%)$ & 0.830 \\
\hline & $\begin{array}{l}\text { Primary } \\
\text { school } \\
\text { diploma }\end{array}$ & $28(56 \%)$ & $26(52 \%)$ & \\
\hline & $\begin{array}{l}\text { High school } \\
\text { diploma }\end{array}$ & $15(30 \%)$ & $18(36 \%)$ & \\
\hline & $\begin{array}{l}\text { College } \\
\text { certificate }\end{array}$ & 0 & $2(4 \%)$ & \\
\hline & $\begin{array}{l}\text { University } \\
\text { certificate }\end{array}$ & $5(10 \%)$ & $2(4 \%)$ & \\
\hline \multirow[t]{3}{*}{ Type of injury } & Penetrating & $29(58 \%)$ & $45(90 \%)$ & 0.001 \\
\hline & Rupture & $11(22 \%)$ & $5(10 \%)$ & \\
\hline & Dehiscence & $10(20 \%)$ & 0 & \\
\hline
\end{tabular}


Table 2 Prevalence of personality disorders in the study population

\begin{tabular}{lcccc}
\hline Type of PD & Total & Case & Control & \\
\hline Cluster A & 100 & 50 & 50 & \\
Paranoid & $\mathbf{1 0}(\mathbf{1 0 . 0 \%})$ & $\mathbf{8}(\mathbf{1 6 . 0 \%})$ & $\mathbf{2}(\mathbf{4 . 0 \%})$ & $\mathbf{0 . 0 4 6}^{\mathrm{a}}$ \\
Schizoid & $1(1.0 \%)$ & $1(2.0 \%)$ & $0(0.0 \%)$ & $>0.99^{\mathrm{b}}$ \\
Schizotypal & $6(6.0 \%)$ & $4(8.0 \%)$ & $2(4.0 \%)$ & $0.678^{\mathrm{b}}$ \\
Cluster B & & & & \\
Antisocial & $\mathbf{3 3}(\mathbf{3 3 . 0 \%})$ & $\mathbf{2 3}(\mathbf{4 6 . 0 \%})$ & $\mathbf{1 0}(\mathbf{2 0 . 0} \%)$ & $\mathbf{0 . 0 0 6}^{\mathrm{a}}$ \\
Borderline & $15(15.0 \%)$ & $10(20.0 \%)$ & $5(10.0 \%)$ & $0.161^{\mathrm{a}}$ \\
Histrionic & $\mathbf{1 5}(\mathbf{1 5 . 0 \%})$ & $\mathbf{1 1}(\mathbf{2 2 . 0 \%})$ & $\mathbf{4}(\mathbf{8 . 0 \%})$ & $\mathbf{0 . 0 5 0}^{\mathrm{a}}$ \\
Narcissistic & $22(22.0 \%)$ & $15(30.0 \%)$ & $7(14.0 \%)$ & $0.053^{\mathrm{a}}$ \\
Cluster C & & & & \\
Avoidant & $8(8.0 \%)$ & $6(12.0 \%)$ & $2(4.0 \%)$ & $0.269^{\mathrm{b}}$ \\
Dependent & $0(0.0 \%)$ & $0(0.0 \%)$ & $0(0.0 \%)$ & $1^{\mathrm{a}}$ \\
OCPD & $4(4.0 \%)$ & $2(4.0 \%)$ & $2(4.0 \%)$ & $1^{\mathrm{a}}$ \\
Cluster A & $\mathbf{1 4}(\mathbf{1 4 . 0 \% )}$ & $\mathbf{1 2}(\mathbf{2 4 . 0 \% )}$ & $\mathbf{2}(\mathbf{4 . 0 \%})$ & $\mathbf{0 . 0 0 4}^{\mathrm{a}}$ \\
Cluster B & $\mathbf{5 3 ( 5 3 . 0 \% )}$ & $\mathbf{3 2}(\mathbf{6 4 . 0 \%})$ & $\mathbf{2 1}(\mathbf{4 2 . 0 \%})$ & $\mathbf{0 . 0 2 8}^{\mathrm{a}}$ \\
Cluster C & $8(8.0 \%)$ & $4(8.0 \%)$ & $4(8.0 \%)$ & $>0.99^{\mathrm{a}}$ \\
\hline PD person & & &
\end{tabular}

$P D$ personality disorder, $O C P D$ obsessive compulsive personality disorder

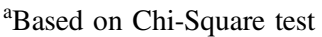

${ }^{b}$ Based on Fisher exact test

Bold values show significant findings

might have been diagnosed with more than one disorder/ trait. Concerning various clusters, cluster B disorders were the most frequent in both groups and significantly more common in the case group $(P=0.028$, Chi-square test). Cluster A disorders were also more common in the case group ( $P=0.004$, Chi-square test). The cluster $\mathrm{C}$ disorders were equally distributed between two groups.

The chance to encounter any personality disorder was $86 \%$ in the case group and 52\% in the control group $(P<$ 0.001 , Chi-square test). The difference between the two groups was statistically significant for antisocial personality disorder (23 [46\%]vs 10 [20\%]; $P=0.006$, Chi-square test). We also found that paranoid personality disorder was significantly more common in the case group $(8[16 \%]$ vs 2 [4\%]; $P=0.046$, Chi-square test). The difference between the two groups was approaching significance for histrionic and narcissistic personality disorders.

The mean visual acuity was $2.41 \pm 0.95$ and $2.05 \pm 1.11$ $\log$ MAR for the case and control groups, respectively $(P=$ 0.044, Mann-Whitney U test). Penetrating injury constituted the most common type of injury in both groups (29 [58\%] in the case and $45[90 \%]$ in the control group $[P<$ 0.001 , Chi-square test]). Globe rupture stepped the second type of ocular injury, with a statistically significant difference in favor of the case group (11 [22\%] versus five [10\%], $[P<0.001$, Chi-square test $])$. Ten patients $(20 \%)$ with
Table 3 Variables in the ocular trauma score (OTS)

\begin{tabular}{llcc}
\hline Visual acuity & & \multicolumn{2}{c}{$\begin{array}{c}\text { Associated } \\
\text { morbidity }\end{array}$} \\
\hline NLP & Rupture & 60 & -23 \\
LP/HM & Endophthalmitis & 70 & -17 \\
CF-19/200 & Perforating injury & 80 & -14 \\
$1 / 10-4 / 10$ & Retinal detachment & 90 & -11 \\
$\geq 5 / 10$ & Afferent pupillary defect & 100 & -10
\end{tabular}

Table 3 (Cont). Calculation of ocular trauma score

\begin{tabular}{ll}
\hline Raw point & Ocular trauma score \\
\hline $0-44$ & 1 \\
$45-65$ & 2 \\
$66-80$ & 3 \\
$81-91$ & 4 \\
$92-100$ & 5 \\
\hline
\end{tabular}

wound dehiscence of previous corneal graft or repair were populating the case group only $(P<0.001)$.

Except for significant difference between two groups in the number of lid lacerations (22 [44\%] in the case group versus nine $[18 \%]$ in the control group $[P=0.005$, Chisquare test]), no difference was observed for the presence of hyphema (38 [76\%] vs 41 [82\%]), lens dislocation (six [12\%] vs one [2\%]), traumatic cataract (11 [22\%] vs $15[30 \%])$, uveal prolapse (32 [64\%] vs $38[76 \%]$ ), traumatic retinal detachment (18 [36\%] vs 13 [26\%]), and orbital bone fracture (4 [8\%] vs 0$)$.

The ocular trauma score (OTS) was calculated for both groups (Table 3). In the case group, scores one, two, three, and four comprised $28(56 \%), 13(26 \%)$, seven (14\%), and two (4\%) patients, respectively. In the control group, scores one, two, and three contained 18 (36\%), 13 (26\%), and 19 (38\%) patients, respectively. The difference in score one (which represents the poorest prognosis) showed to be statistically significant between two groups $(P=0.028$, Mann-Whitney U test).

\section{Discussion}

Our study showed that two groups were similar regarding their age and gender. All participants were in a productive age range. More than half of patients had OTS one or two, which means living the rest of their lives with ocular morbidity.

The difference in the marital status observed in our study is noteworthy. We found that single participants were more likely to injure in a violent act. We defer investigating various aspects of this correlation to future 
studies. Also, the controls in our study showed more penetrating injuries in contrast to the more globe ruptures observed in the case group. This difference reflects the mechanism of injury in each group: The injury in the control group was mainly a result of work-related accidents; fist punch and blunt objects were the leading causes of trauma in the case group.

The better visual outcomes detected in the control group may be related to the use of protective equipment in the settings other than violence. This also explains why the controls had significantly fewer eyelid lacerations in our study. Overall, the severity of ocular damage was more in the case group. The most miserable OTS outcome was correlated with the violence-related eye injury. It appears that in domestic or public violence, the motivation for causing damage may bring in the persisting and forceful behavior of harm that seems to result in more adversity.

The Diagnostic and Statistical Manual of Mental Disorders (DSM) version 5 was introduced in late 2012. While previous versions had categorized personality disorders under axis-II diseases, in DSM-V this axis has been omitted and personality disorders are now considered alongside the other previously categorized axis I disorders. Despite extensive discussions and promotions in order to change into a dimensional approach instead of the previously categorical approach, DSM-V had ultimately retained the same categorization and diagnostic criteria of PDs as same as previous versions. Of note, however, under section III a new hybrid model was introduced to encourage clinicians to consider impairments in identity and interpersonal efficiency as part of diagnosis of personality disorders/traits. This approach is helpful in the diagnosis of a patient whose features/traits are partially matched with strict categorical criteria or who has a variable and/or prominent symptomatology [17, 18].

Table 4 categorizes the characteristics of PDs according to DSM-V criteria and their prevalence in the community.
In community-based studies, the prevalence of any PD has been estimated to be $4.4-13 \%$ [19]. A recently published meta-analysis by Volkert and colleagues reported the prevalence of any personality disorder among general adult population about 12 percent [20].

The sample of our study was smaller than necessary for a good estimation of prevalence; however, we found that antisocial PD was the most common, followed by narcissistic, histrionic, paranoid, and borderline PDs. We found that paranoid and antisocial PDs were significantly more common in the violence-related population. Also, the near-significant difference between two groups detected for narcissistic and histrionic PDs should be evaluated with further studies to avoid unnecessary extrapolations.

The epidemiology of violence-related eye injury is not known in Iran [21]. In one study in China $14 \%$ of eye injuries resulted from violence [22]. Although epidemiological data are lacking in many parts of the world, the results of available surveys show that up to one-third of eye injuries may result from the strike by an object or person $[4,5,23]$. In a study by Rahman et al., $45 \%$ of open globe injuries were the result of an assault [6].

A question as to whether a causal relationship exists between violence and personality disorders is difficult to be answered. One reason is that violence is a multifactorial phenomenon and simple attribution to the presence of a personality disorder is best avoided [10, 11]. Also, aggressive and/or violent behaviors are inherent in some personality disorders' diagnostic criteria. Hence, care should be taken to draw causality deduction between PDs and violence.

In a study by Coid et al., retrospective assessment of patients admitted to forensic psychiatry services in a 6-year period was performed [24]. They found $16 \%$ of the participants had some personality disorders, with cluster B constituting the most common (44\% antisocial and 35\% borderline PDs). We also found cluster $\mathrm{B}$ as the most

Table 4 Characteristics of personality disorders according to DSM-V criteria

\begin{tabular}{|c|c|c|c|}
\hline Cluster type & $\begin{array}{l}\text { Sub-cluster } \\
\text { disorder }\end{array}$ & Shared points & $\begin{array}{l}\text { Percent in the } \\
\text { community }\end{array}$ \\
\hline A & $\begin{array}{l}\text { Paranoid } \\
\text { Schizoid } \\
\text { schizotypal }\end{array}$ & $\begin{array}{l}\text { Distorted thinking with odd and eccentric behavior leading to social awkwardness and } \\
\text { withdrawal }\end{array}$ & $\begin{array}{l}0.7-2.4 \\
0.4-1.7 \\
0.1-5.6\end{array}$ \\
\hline B & $\begin{array}{l}\text { Antisocial } \\
\text { Histrionic } \\
\text { Narcissistic } \\
\text { borderline }\end{array}$ & $\begin{array}{l}\text { Disrupted impulse control and emotional regulation leading to dramatic, emotional, and } \\
\text { erratic behavior }\end{array}$ & $\begin{array}{l}0.6-3 \\
2.1 \\
0.4-0.8 \\
0.7-2\end{array}$ \\
\hline $\mathrm{C}$ & $\begin{array}{l}\text { Avoidant } \\
\text { Dependent } \\
\text { Passive- } \\
\text { aggressive }\end{array}$ & High level of anxiety and fearfulness & $\begin{array}{l}0.8-5 \\
1.0-1.7 \\
1.7-2.2\end{array}$ \\
\hline
\end{tabular}


common class of PDs with antisocial, narcissistic, histrionic, and borderline PDs in decreasing order. The antisocial PD was significantly more common in the case group.

Warren et al. studied 250 female prisoners according to SCID II and classified 200 patients with cluster B personality disorder [25]. They reported antisocial, paranoid, and borderline PDs in decreasing order of prevalence. Their findings showed that there was a significant correlation between narcissistic PD and violent behavior: they were eight times more vulnerable to acting violently. Our study showed a higher number of narcissistic PD in the case group, though the difference was not significant. Warren's study did not include any male participants, and the population was merely registered from prisoners thus less generalizable to public patients.

Johnson et al. performed an interview with 717 randomly selected adolescents and their mothers and reported $14 \%$ PD among them [26]. Those with PDs had committed violence significantly more in comparison to the remaining participants. Similar to our study, cluster B was most common, followed by cluster A and cluster C. They reported that paranoid and narcissistic PDs were twice as likely to involve in violent behavior. Nevertheless, they did not investigate antisocial PD as a matter of the young age of the participants. Although cluster $\mathrm{C}$ personality disorders were not found to be associated with increased risk of violence, passive-aggressive PD was explicitly associated with a higher risk of violence, a result that differs with our findings. The Johnson's study was included only adolescent population, which limits its generalizability for other age groups.

\section{Limitations}

According to DSM-V criteria, diagnosis of PDs requires exclusion of substance abuse. In our study, no objective test was used to rule out substance abuse, and the diagnosis was solely made based on the judgment of the interviewer and the statements of the patients.

One may hardly succeed in the exact definition of the role of various parameters in those who have committed or victimized by violence.

On the other hand, assessment of the violence may be quite tricky. There are some instances in which the legal burden of such behaviors may provoke their denial. For example, we cannot say for sure how many patients in our study were injured due to domestic violence or criminal act.

Finally, we believe that the small sample size in our study limits interpretation of results regarding epidemiological data and estimation of the significance of difference observed for some personality disorders.

\section{Conclusion}

The findings of our study propose that some personality disorders/traits are probably important factors in those who acquire open globe injury during violent behavior. We suggest that this population merits appropriate psychiatric consultation for detection of personality disorders.

\section{Summary}

\section{What was known before}

- In spite of apparent association between psychopathologic conditions and personality disorders, it is less known as to whether PDs prone non-psychiatric population to medical comorbidities.

\section{What this study adds}

- In this report, we will discuss personality disorders among patients with an open globe injury related to violent behavior. We will compare this group with another group of patients with open globe injuries not involved in violence.

\section{Compliance with ethical standards}

Conflict of interest The authors declare that they have no conflict of interest.

Publisher's note: Springer Nature remains neutral with regard to jurisdictional claims in published maps and institutional affiliations.

\section{References}

1. Bhogal G, Tomlins PJ, Murray PI. Penetrating ocular injuries in the home. J Public Health (Oxf). 2007;29:72-4.

2. Channa R, Zafar SN, Canner JK, Haring RS, Schneider EB, Friedman DS. Epidemiology of eye-related emergency department visits. JAMA Ophthalmol. 2016;134:312-9.

3. National Institute for Occupational Safety and Health (NIOSH). Healthy People 2010. Vision. Fact Sheet: Eye Safety at Work is Everyone's Business (2010). https://nei.nih.gov/news/pressrelea ses/060100.

4. Owens PL, Mutter R. Emergency Department Visits Related to Eye Injuries, 2008 Statistical Brief \#112. Healthcare Cost and Utilization Project (HCUP) Statistical Briefs. https://www.ncbi. nlm.nih.gov/books/NBK56035/.

5. Nash EA, Margo CE. Patterns of emergency department visits for disorders of the eye and ocular adnexa. Arch Ophthalmol. 1998;116:1222-6.

6. Rahman I, Maino A, Devadason D, Leatherbarrow B. Open globe injuries: factors predictive of poor outcome. Eye (Lond). 2006;20:1336-41. 
7. Bradley K. The Bradley Report: Lord Bradley's Review of People with Mental Health Problems or Learning Disabilities in the Criminal Justice System. London: Department of Health; 2009.

8. Negrel AD, Thylefors B. The global impact of eye injuries. Ophthalmic Epidemiol. 1998;5:143-69.

9. Samuels J. Personality disorders: epidemiology and public health issues. Int Rev Psychiatry. 2011;23:223-33.

10. Durcan G, Saunders A, Gadsby B, Hazard A. The Bradley Report five years on: An independent review of progress to date and priorities for further development. Centre for Mental Health. 134-138 Borough High Street, London SE1 1LB, 2014.

11. Short V, Lennox C, Stevenson C, Senior J, Shaw J. Mental Illness, Personality Disorder and Violence: A Scoping Review. The Offender Health Research Network, University of Manchester, 2012.

12. Davison S, Janca A. Personality disorder and criminal behaviour: what is the nature of the relationship? Curr Opin Psychiatry. 2012;25:39-45.

13. First MB, Gibbon M, Spitzer RL, Williams JBW, Benjamin LS. Structured Clinical Interview for DSM-IV Axis II Personality Disorders (SCID-II). Washington, DC: American Psychiatric Press, Inc; 1997.

14. Akbari Dehaghi A, Kaviani H, Tamanaeefar S. Problem-solving deficits in Iranian people with borderline personality disorder. Iran J Psychiatry Behav Sci. 2014;8:12-8.

15. Matini D, Ghanbari Jolfaei A, Pazouki A, Pishgahroudsari M, Ehtesham M. The comparison of severity and prevalence of major depressive disorder, general anxiety disorder and eating disorders before and after bariatric surgery. Med J Islam Repub Iran. 2014;28:109.

16. Sharifi V, Assadi SM, Mohammadi MR, Amini HA, Kaviani H, Semnani Y, et al. Structured clinical interview for DSM-IV
(SCID): Persian translation and cultural adaptation. Iran J Psychiatry. 2007;2:46-48.

17. Guelfi JD. A perspective on the current issues in the DSM-5 classification of personality disorders. Dialog- Clin Neurosci. 2013;15:131-2.

18. Oldham JM. The alternative DSM-5 model for personality disorders. World Psychiatry. 2015;14:234-6.

19. Coid J. Epidemiology, public health and the problem of personality disorder. Brit J Psych. 2003;182(suppl. 44):3-10.

20. Volkert J, Gablonski T-C, Rabung S. Prevalence of personality disorders in the general adult population in Western countries: systematic review and meta-analysis. Br J Psychiatry. 2018;213:709-15. https://doi.org/10.1192/bjp.2018.202.

21. Aghadoost D, Fazel MR, Aghadoost H, Aghadoost N. Pattern of ocular trauma among the elderly in Kashan, Iran. Chin J Traumatol. 2013;16:347-50.

22. Cao H, Li L, Zhang M. Epidemiology of patients hospitalized for ocular trauma in the Chaoshan Region of China, 2001-2010. PLoS ONE. 2012;7:e48377.

23. Jha KN. Ocular trauma has fallen on our blind spot. J Clin Ophthalmol Res. 2016;4:65-9.

24. Coid J, Kahtan N, Gault S, Jarman S. Patients with personality disorder admitted to secure forensic psychiatry services. Br J Psychiatry. 1999;175:528-36.

25. Warren J, Burnette M, South S, Chauhan P, Bale R, Friend R. Personality disorders and violence among female prison inmates. J Am Acad Psychiatry Law. 2002;30:502-9.

26. Johnson J, Cohen P, Smailes E, Kasen S, Oldham J, Skodol A, et al. Adolescent personality disorders associated with violence and criminal behaviour during adolescence and early adulthood. Am J Psychiatry. 2000;157:1406-12. 